\section{What do you think?}

$\mathrm{T}$ his year the DMJ team has spent most of its time thinking outside the box. Unlike our national medical journal, the CMAJ, we added to our editorial board rather than fired it. New to our staff is the position of Freelance Editor, the student responsible for the recruitment of individuals and stories that hope to shape, inspire and most certainly excite our readers.

An advisory board consisting of 9 members including a number of Deans from various health and research related activities of Dalhousie has also been established. We hope this will provide the necessary guidance, vision and consistency as the student editorial board renews itself each year.

The underlying tone throughout this issue is that of medical education. From the application process to the future of health care, we explore many avenues that shall be of interest to future and current students as well as the broader Atlantic communities.

Last summer I contemplated whether or not a medical school's definition of 'well-roundedness' happens to be reflective of a family's disposable income. I assumed that individuals with extensive applications are provided with such opportunities because their family was able to support their volunteer and travel desires. Vanessa Rich surveyed over 200 Dalhousie students, concluding that the family income does not differentiate the number of extracurricular activities on one's application.

Classmate Ashley McCormick, the one who reminds me the most of Dr. Jacques Ferron, loses sleep struggling to deal with barriers of medical school accessibility. Deciding medicine as a career is not a last minute decision - many authors in this issue well tell you that. For most it is a significant part of one's youth, devoted to experiences and reflections that are later assembled and shared with the admissions committee. The spark to practice medicine could arguably be either unique or universal within all of us. However, the constant fuel to encourage this dream is the real McCoy of accessibility. Such encouragement comes from our family, friends, educators and community. Jen Ahmed has introduced us to the barrier within the Aboriginal community, inviting us to work towards knocking down such barriers and resolving McCormick's anguish.

I have concluded that the future of medical education lies in the ovaries of our future mothers. However, a number of current players will take part in shaping the knowledge and paths of these future physicians. Ryan Sommers hints that the current struggle between private and public health care will trump the progress of medical education and may even exclude it. In order to develop a health care system that supports the values of Tommy Douglas and most importantly, one that is socially acceptable, we must find a way to selflessly think about the long term. This will require both research and action on evidence and not just values. Dr. Kronick addresses the future education of medicine in the Atlantic region. Until all is settled, let our education be provided by the creative style of Jocelyn Silvester and the life experiences of Kelsey Cameron.

When roaming through my Clerkship Manual for Internal Medicine I discovered this quote: "No one is listening until you make a mistake." I presume the same goes for reading. Thus, although much has been done to avoid errors, should you find any material conflicting with your own wisdom or be provoked by the following content in this issue, please write to us atdmj@dal.ca. Your correspondence means you have read this issue and therefore I have done my job correctly.

\section{Andrew Howlett \\ Senior Editor-in-Chief, DMJ}

